\title{
10 Von Kumanen, Polowzern und Kiptschaken
}

\begin{abstract}
Da stieg der Fürst Igor in den goldenen Steigbügel und ritt über das freie Feld. Die Sonne vertrat ihm mit Dunkel den Weg; die Nacht aber, aufstöhnend in Unwettern, machte ihm die Vögel wach, der Tiere pfeifendes Schreien scheuchte sie in Scharen auf. Heulend erhob der Drache sich über die Bäume hin und zwang fremde Länder in seinen Schrei: die Wolga, die Landstriche am Meer und die Sula entlang, Sudak und Korsun und dich, Götzen von Tmutorakan. Und die Polowzer zogen auf unfahrbaren Wegen an den großen Don. Ihre Wagen kreischten in der halben Nacht wie Schwäne, die sich verflogen haben. ${ }^{1}$
\end{abstract}

Die von Rainer Maria Rilke (1875-1926) besorgte Nachdichtung des berühmten „Igor-Lieds“ („Slovo o polku Igoreve“) gehört zwar nicht zu den in wissenschaftlicher Hinsicht maßgeblichen Übersetzungen dieses ursprünglich in altostslavischer Sprache verfassten Sprachdenkmals, ${ }^{2}$ aber sicher zu den schönsten. Von einem Teil der historischen und linguistischen Forschung wurde (und wird) die Authentizität des „Igor-Lieds“ immer wieder in Zweifel gezogen, ${ }^{3}$ eine Mehrheit hält die Erzählung über den erfolglosen Feldzug des Novgoroder Fürsten Igor Svjatoslavič (1151-1201) im Jahr 1185 gegen die Polowzer und dessen Klage über die Zerstrittenheit der Fürsten der Kiewer Rus' aber für echt und zeitnah nach den beschriebenen Ereignissen verfasst; so etwa der große sowjetische Mediävist Dmitrij S. Lichačëv (1906-1999) ${ }^{4}$ oder der Linguist A.A. Zaliznjak (1935-2017). Auf der Basis einer Sprachanalyse des Epos kam dieser zu dem Ergebnis, dass eine Fälschung zwar nicht absolut unmöglich sei, aber dies nur unter der Annahme, „dass sie von einem ausgesprochenen Genie ausgeführt“ worden sei. ${ }^{5}$ Wie auch immer, für unseren Kontext ist die Erwähnung Tmutarakan's und der an der Südküste der Krim gelegenen Städte Sudak (russ./ukr.; krimtat. Sudaq) ${ }^{6}$ und Korsun'/Chersones von Bedeutung. Diese ist geeignet, einmal mehr die Existenz von Verbindungen zwischen der Halbinsel und der Rus' zu untermauern. Zwischen diese beiden Akteure hatte sich allerdings ein weiterer geschoben, wie uns das Epos berichtet: die Polowzer (wie es in slavischen Überlieferungen heißt ${ }^{7}$ oder Kumanen (so in turksprachigen Quellen) bzw. Kiptschaken/Qipčak (in isla-

1 Igor-Lied (1989), $14 \mathrm{f}$.

2 Lied (1989).

3 Vgl. z.B. Filip (1990).

4 Vgl. z.B. Lichačëv (1985).

5 Zaliznjak (2008).

6 In der altoslavischen Version wird die slavische Variante Sudaks - „Surož“ - verwendet, vgl. z. B. Igor-Lied (1989), 42. Eine weitere in der Zeit gebrauchte Variante lautet „Soldaia“ bzw. „Sugdeja“ (griech.).

7 Im Folgenden wird diese Bezeichnung verwendet.

๑ OpenAccess. ( 2020 Kerstin S. Jobst, publiziert von De Gruyter. (cc))BY Dieses Werk ist lizenziert unter der Creative Commons Attribution 4.0 International. https://doi.org/10.1515/9783110520620-012 
mischen Schriftquellen). ${ }^{8}$ Wieder einmal war ein - erneut turksprachiger Reiterverband aus dem eurasischen Raum in das heute russische/ukrainische Steppengebiet vorgedrungen und übte von dort aus Einfluss auf die Geschicke der Krim aus, indem er im Verlauf des 11. Jahrhunderts die Handelsrouten zu kontrollieren begann. Auch in diesem Fall war er durch seine Mobilität - „Und die Polowzer zogen auf unfahrbaren Wegen an den großen Don“, so heißt es im „IgorLied“ - seinen Gegnern gegenüber im Vorteil. Politisch zeigte sich auch dieser Herrschaftsverband flexibel und etablierte z. B. Handelskontakte mit Byzanz, in denen Sudak eine gewichtige Rolle als wirtschaftliche Drehscheibe spielte. Auch die Beziehungen zur Rus' verbesserten sich ab dem 13. Jahrhundert (also in den Jahrzehnten nach dem Feldzug Igors) und es kam zu zahlreichen ehelichen Verbindungen und militärischen Bündnissen.

Gerade letztere wurden in der Folge wichtig: Als ein Vorbote des im russischen kollektiven Bewusstsein so wirkungsmächtigen sog. Mongolensturms ${ }^{9}$ wird ein 1223 erfolgter Einfall der Mongolen auf die Krim angesehen, wo diese u. a. eben Sudak verwüsteten. Die Bedrohung durch diese Invasoren festigte den Bund zwischen den Polowzern und der Rus' nachhaltig: In der Schlacht an der Kalka (in der heutigen südöstlichen Ukraine) im Mai 1223 versuchten die nun geeinten Herrscher der Teilfürstentümer der Kiewer Rus' die Invasoren gemeinsam mit den Verbündeten zu schlagen. Sie scheiterten kläglich, ihre Bezwinger allerdings zogen - vorerst - wieder ab. ${ }^{10}$ Als die mongolisch-tatarischen Sieger dann eineinhalb Jahrzehnte später abermals nach Westen vorstießen und dauerhaft blieben, leitete dies den endgültigen Niedergang der Dominanz der Polowzer in der nördlichen Krim und den angrenzenden Steppenregionen ein. Ein Teil akkulturierte sich in der Folge an die Kultur, Ökonomie und Lebenswelten der neuen Herren bzw. man verwandelte sich wechselseitig aneinander an, andere wiederum zogen westwärts; sie folgten somit einem in der Krim-Geschichte etablierten Muster. Die mongolischen Eindringlinge zeigten großes Potential: Batu Chan (1205-1255), Enkel des Činggis Qayan (Dschingis Chan; um 1155, 1162 oder 11671227), dem die Vereinigung der bis dahin separiert agierenden mongolischen Stämme gelungen war, hatte bei seinem Vorstoß Richtung Westen einen ambi-

8 Vgl. einführend Golden (2003).

9 Vgl. z.B. die Deutung des slavisch-asiatischen Encounters durch den zur sog. Eurasischen Strömung in der russischen Geistesgeschichte gehörenden Historiker George Vernadsky: Vernadsky (1969).

10 Magocsi (2014), $27 \mathrm{f}$., ist der Auffassung, dass die mongolisch-tatarischen Truppen in dieser Schlacht wertvolle Erkenntnisse gewonnen hatten, die sie Ende der 1230er Jahre verwerten konnten: „This time they came with a massive military force estimated at between 120.000 and 140.000 troops under the supremecommand of Chinggis Khan's grandson, Khan Batu.“ 
tionierten Plan verfolgt: „to conquer the divided land of quarreling Rus' [...] princes, the lands of Turkish Bulgars and Kipchaks and the Christian lands of Eastern Europe“, wie es der Orientalist Brian G. Williams zusammenfasst. ${ }^{11}$ Tatsächlich gelang es Batu Chan, die mongolisch-tatarische Herrschaft weithin am Schwarzen Meer und auf weite Teile der Rus' (ausgenommen den Nordwesten) auszudehnen und von der an der unteren Wolga gegründeten Stadt Sarai aus zu administrieren. Von der lange Zeit dominierenden Vorstellung des sprichwörtlich gewordenen „Mongolenjochs“, welches so schwer auf den ostslavischen Gebieten gelastet haben soll, hat sich die Forschung übrigens partiell verabschiedet, allerdings ohne die gewaltgenerierenden Aspekte $\mathrm{zu}$ negieren. In der Goldenen Horde herrschte, ebenso wie in den anderen mongolischen Teilreichen, beispielsweise religiöse Toleranz, oder besser gesagt: „dem Khan war die Religion der unterworfenen Völker gleichgültig.“ Überdies wurde nicht versucht, „die sprachlichen, rechtlichen, wirtschaftlichen, sozialen oder kulturellen Verhältnisse $\mathrm{zu}$ vereinheitlichen. “12

Das Zentrum der Horde auf der Krim wurde Eski Qırım (krimtat.: „Alte Festung“") genannt - so lautete der neue Name von Solcati, wie die Stadt von den auf die Halbinsel gekommenen Italienern, auf die noch genauer einzugehen sein wird, genannt worden war. Ehe die Neuankömmlinge aus dem Osten die Stadt einnahmen, war sie - wie auf der Krim ja üblich - ethnisch und kulturell vielfältig gewesen, lebten dort doch neben romanischen und turksprachigen BewohnerInnen ebenso Nachfahren der griechischen Kolonisten oder auch Armenier, die über ein weit gespanntes Netz aus Händlern verfügten. Die heute Staryj Krym (ukr./russ.: „Alte Festung“ bzw. „Alte Krim“) genannte Siedlung liegt strategisch günstig zwischen den südlichen Ausläufern des Krim-Gebirges und der nördlichen Steppenregion im Osten, so dass von dort aus eine umfassende Kontrolle weiter Teile der Halbinsel möglich war.

In der Küstenregion wiederum hatten sich die Machtverhältnisse zu Beginn des 13. Jahrhunderts grundlegend geändert, denn die Herrschaft Konstantinopels über seine Außenposten wie Chersones endete. Was war geschehen? Die KrimStädte im Süden hatten sich lange dem immer wieder anschwellenden Druck nomadischer Verbände mit mehr oder weniger großem Erfolg erwehren können bzw. Modi des Ausgleichs mit diesen gefunden. Insbesondere in Chersones hatte sich auch deshalb das Christentum früh - wie schon dargelegt - durchsetzen können. Die Oberhoheit der christlichen Macht Byzanz war dort über die Zeit

11 Williams (2001), 11.

12 Haumann (1996), $98 \mathrm{f}$. 
weder von den ursprünglich wohl schamanischen Religionen der Polowzer ${ }^{13}$ noch vom Judentum (Chasaren) oder dem Islam anhängenden BewohnerInnen aus dem Norden wirklich herausgefordert worden. Die Rolle des Totengräbers der byzantinischen Krim fiel indes den eigenen Glaubensbrüdern zu.

13 Williams (2001), 11. 